\title{
TERMINAIS DE CONTÊIINERES NO BRASIL: EFICIÊNCIA INTERTEMPORAL
}

\author{
Leopoldo Heitor Capelini Kirchner * \\ Vander Mendes Lucas ${ }^{\dagger}$
}

\begin{abstract}
Resumo
A evolução recente do setor portuário brasileiro tem levado a impactos significativos sobre a concorrência e sobre a expectativa de maiores ganhos de eficiência. Considerando o valor médio das eficiências nos três anos de análise, na fronteira de eficiência permaneceram dois terminais de grande porte (Tecon Santos Brasil e Libra Terminais - Santos) e um terminal de menor porte (TUP Chibatão). A análise intertemporal através do índice de Malmquist mostra que o índice de mudança de tecnologia do Tecon Santos Brasil caiu. Isso significa que os inputs estão sendo utilizados de uma maneira menos eficiente que no período anterior.
\end{abstract}

Palavras-chave: Eficiência Portuária; DEA; Índice de Malmquist.

\begin{abstract}
The recent evolution of the Brazilian port sector has led to significant impacts on the competition and the expectation of further efficiency gains impacts. By considering the average value of efficiencies in the three years of analysis, two large terminals (Tecon Santos and Libra Terminals - Santos) remain on the efficiency frontier. The intertemporal analysis using the Malmquist index shows that this rate for the Tecon Santos Brasil fell. This means that the inputs are being used by the port terminals in a less efficient way than in the previous period.
\end{abstract}

Keywords: Port Efficiency, Data Envelopment Analysis, Malmquist Index. JEL classification: L25, L62, L91, R41

DOI: http://dx.doi .org/10.11606/1980-5330/ea132525

\footnotetext{
* Analista de Regulação da ANTAQ. E-mail: leopoldo.kirchner@antaq.gov.br.

† Professor do Departamento de Economia da Universidade de Brasília. E-mail: vlucas@unb.br.
} 


\section{Introdução}

Em um passado não muito distante portos prestavam serviços intensivos em trabalho. Porém, eles passaram por grandes mudanças que os tornaram intensivos em capital, o que os levaram à especialização no transporte de diferentes tipos de carga. Em suma, a evolução recente do setor portuário brasileiro pode ser dividida em três momentos históricos ${ }^{1}$. O primeiro iniciou-se em 1934 e foi caracterizado por um modelo estatal de gestão portuária. O segundo tem como marco histórico a promulgação da Lei n 8.630/93 ("Lei dos Portos") em 1993, que propiciou a abertura do setor ao capital privado. E o terceiro começou em 2012 com a publicação da Medida Provisória no 595/2012, convertida na Lei 12.815 de 5 de junho de 2013, que estendeu a abertura à participação privada no setor portuário ao eliminar restrições ainda existentes à constituição de terminais de uso privativo. Conforme observamos abaixo, as reformas no setor indicam uma tendência de maior participação privada, com impactos significativos sobre a concorrência e sobre a expectativa de maiores ganhos de eficiência (Coutinho et al. 2012).

Apesar da divisão nestes três momentos históricos em suma o que se observou foi que o transporte marítimo através de contêineres, por exemplo, reduziu substancialmente o custo de movimentação de carga e, também, diminuiu o tempo necessário para embarque e desembarque de navios levando a uma maior eficiência principalmente com o uso de equipamentos especializados. Com isso, análises de eficiência de portos e/ou terminais cresceram muito nesses últimos anos ${ }^{2}$.

Em sua dissertação, Fontes (2006) apresenta um modelo em DEA (Data Envelopment Analysis) para calcular valores numéricos para mensurar a eficiência portuária. O autor levou em consideração a movimentação total de cargas nos portos, independentemente da natureza ou do acondicionamento. O período de análise foi 2002-2004 e foram estudados 31 portos e terminais totalizando assim 93 DMUs (Decision Making Units). A modelagem escolhida foi DEA - BCC orientada a output ${ }^{3}$. O input do modelo foi a extensão total de cais aportáveis e os outputs do modelo foram a movimentação total de embarcações e movimentação total de carga transportada dentro e fora do cais. Ele chegou a oito DMUs com valor máximo de eficiência: Areia Branca (2002 e 2004), Rio Grande (2004), Santarém (2002), Santos (2003 e 2004), São Sebastião (2004) e Tubarão (2004).

Todos os dados do estudo de Fontes foram dispostos em uma mesma análise. Isso permitiu que se aumentasse o número de DMUs, e como o número de variáveis foi pequeno (um input e dois outputs), os resultados obtidos através de DEA - BCC apresentaram uma discriminação bem satisfatória. Com relação às DMUs e variáveis escolhidas, Fontes considerou a movimentação do porto como um todo, não importando qual a natureza da carga (granel sólido, granel líquido, carga geral ou contêineres).

\footnotetext{
${ }^{1}$ Veja Coutinho et al. (2012) para uma descrição destes períodos de evolução dos portos no Brasil.

${ }^{2}$ Veja Coutinho et al. (2012) para uma resenha detalhada da literatura internacional de aplicações de análises de eficiência portuária através de DEA.

${ }^{3}$ Os modelos são CCR (Charnes et al. 1978) e BCC (Banker et al. 1984). O modelo CCR supõe uma fronteira com retorno constante de escala. Já o modelo BCC admite que a superfície de fronteira de produção apresente retornos variáveis de escala.
} 
Fernandes (2010) analisa a eficiência portuária para 2008 restrita a 21 terminais de contêineres, sejam estes públicos ou privados. A modelagem escolhida foi DEA - BCC orientada a output onde os inputs do modelo foram comprimento do cais, área do terminal e número de equipamentos e o output do modelo foi movimentação total de contêineres em TEU. O autor chegou a cinco DMUs com valor máximo de eficiência no modelo CCR orientado a output, sem restrição de pesos: Teconvi, Tecon Salvador, T-37, Tecon Santos e Tecondi. Ao utilizar o modelo BCC orientado a output o resultado passou para nove DMUs eficientes: Teconvi, Tecon Salvador, T-37, Rodrimar, Tecon Santos, Tecondi, CP São Francisco do Sul, Pecém e Superterminais.

Coutinho et al. (2012) investigou a existência de retornos crescentes de escala e eficiência de terminais para o ano de 2010. Foram estudados 15 terminais, públicos e privados, totalizando assim 15 DMUs. A modelagem escolhida: DEA - BCC orientada a output onde os inputs do modelo foram investimentos em máquinas e equipamentos, despesas administrativas e custos de serviços prestados e o output do modelo foi a movimentação total de contêineres em TEU.

Quanto à eficiência dos terminais pesquisados no estudo, nota-se que na modelagem CCR apresentaram-se como eficientes os terminais de Paranaguá e Pecém. Já na modelagem BCC, além dos dois já citados apareceram na relação o Tecon Santos Brasil, a Libra Terminais (SP) e o Teconvi. Quando se comparam os resultados obtidos anteriormente com este trabalho, percebe-se que dependendo das variáveis que são utilizadas na análise, o resultado pode ser bem diferente. O estudo realizado pela UnB utilizou basicamente de variáveis financeiras para determinar a eficiência dos terminais, enquanto neste trabalho foram utilizados variáveis físicas e indicadores operacionais.

Considerando a modelagem CCR, Coutinho et al. (2012) mostra que o Terminal de Contêineres de Paranaguá (TCP) apresentou uma eficiência média de $77,90 \%$ nos três anos de estudo e o Terminal de Pecém apresentou uma média de $41,27 \%$. Terminais considerados eficientes neste trabalho não obtiveram um bom resultado na análise feita pela UnB. Naquele estudo, sempre considerando a mesma modelagem, o Tecon Santos Brasil apresentou uma eficiência de 75,90\%, a Libra Terminais (SP) mostrou uma eficiência de 36,10\% e o TUP Chibatão obteve uma eficiência de $41,00 \%$.

Quando se observam os resultados obtidos através da modelagem escolhida naquele estudo, percebe-se que os terminais que alcançaram a eficiência também o fizeram neste trabalho. Novamente é preciso destacar que a modelagem BCC neste trabalho apresentou mais de $70 \%$ dos terminais estudados como eficientes.

Fernandes (2010) tem como objetivo avaliar a evolução da produtividade de 23 portos e terminais privativos através do índice de Malmquist, comparando os dados de 2008 com o período de 2005. A análise não se restringiu à movimentação de contêineres, sendo considerada a movimentação total da instalação portuária, independente da natureza da carga. Os inputs do modelo são comprimento do cais, área do terminal e quantidade de trabalhadores portuários avulsos (TPAs) e os outputs do modelo: movimentação total de carga geral, de granel sólido e granel líquido. É importante destacar que a análise deste artigo foi feita sem uma discriminação por natureza da carga. A produtividade de um terminal, assim como a eficiência, é geralmente muito diferente em termos de valores, dependendo da natureza da carga que está sendo operada. 
O trabalho de Fernandes mostrou que, em média, os portos brasileiros tiveram um aumento em sua produtividade. Se considerarmos apenas aqueles portos que possuem uma movimentação significativa de contêineres, para podermos comparar com este trabalho, os que obtiveram melhor desempenho foram os Portos de Itaguaí, Paranaguá, Rio de Janeiro, Salvador, Santos, Suape e Vitória. Considerando uma janela de dois anos $(2010 \rightarrow 2012)$, os terminais que apresentaram acréscimo de produtividade foram o TUP Portonave, o Tecon Sepetiba (Porto de Itaguaí), a APM Terminais (Porto de Itajaí), o Multiterminais (Porto do Rio de Janeiro) e o Tecon Suape (Porto de Suape).

Em termos de análise nacional, em ambos os estudos foram apontados aumento de produtividade. Este aumento foi mais significativo entre o período de 2005 a 2008 do que no período de 2010 a 2012. Quando decompomos o índice de Malmquist, no trabalho de Fernandes, tanto a mudança de eficiência quanto a mudança de tecnologia apresentaram desempenhos positivos. Entretanto, neste trabalho, o índice de mudança de tecnologia apresentou um pequeno regresso, mas este foi compensado pelo bom desempenho do índice de mudança de eficiência.

Silva et al. (2011) tratam da evolução da produtividade dos portos organizados através do índice de Malmquist, comparando os dados de 1999 e 2000. A análise teve restrição à movimentação de contêineres e carga geral em 18 portos brasileiros. Os inputs do modelo foram largura da bacia de evolução, largura do canal de acesso, profundidade do canal de acesso, comprimento de cais acostável e profundidade do cais acostável. Já os outputs do modelo foram movimentação total de carga geral e contêineres. Tanto para análise de eficiências em um dado momento como durante um período foram considerados retornos constantes de escala. O artigo mostra que a produtividade dos portos aumentou no período analisado. Para a movimentação de contêineres, os Portos de Fortaleza, Itajaí, Manaus, e Salvador obtiveram crescimento no índice de Malmquist. No caso de carga geral, o estudo mostrou que 11 portos apresentaram aumento de produtividade. O estudo de Silva et al. (2011) também procurou identificar outliers na amostra analisada, excluindo assim os dados referentes aos Portos de Santos e Itaqui (1999) e Paranaguá, Rio Grande e Rio de Janeiro (2000).

Este artigo está estruturado como segue. A Seção 2 faz uma contextualização sobre a movimentação de cargas no Brasil, dando enfoque à movimentação de contêineres e sua evolução ao longo dos últimos anos. São apresentados, de forma sintética, alguns dos principais portos que movimentam este tipo de carga, e que estarão presentes na análise de eficiência. A Seção 3 expõe a metodologia de análise de eficiência através da análise envoltória de dados - DEA e do índice de Malmquist. Sobre DEA serão feitas abordagens das principais definições, a seleção de variáveis para análise e a escolha da modelagem ideal para o tema em questão e sobre o índice de Malmquist serão abordadas sua formulação específica bem como o significado desse índice e de suas decomposições. A Seção 4 trata da aplicação detalhada de DEA e do índice de Malmquist nos principais terminais de contêineres do Brasil e compara os resultados obtidos com alguns trabalhos realizados neste tema. Por fim, as conclusões. 


\section{O Setor Portuário Brasileiro}

Movimentações portuárias de carga no Brasil mostram que nos anos recentes houve crescimento no país, exceto no ano de 2008 devido ao período da crise financeira mundial. Em 2000 o país movimentou em seus portos 484.660 .640 toneladas, enquanto que em 2012 esse valor chegou a 903.765 .474 toneladas, o que significa um aumento de $86,5 \%$ em 12 anos. Fundamentalmente, o Brasil é um grande movimentador de granéis sólidos e, em média, 60\% das mercadorias que passam pelos portos são dessa natureza. Todavia é na carga geral onde se encontra o maior valor agregado das mercadorias, visto que é nessa categoria que se encontra a movimentação de contêineres.

Os portos organizados são os maiores movimentadores de contêineres do país. Geralmente, em cada um dos portos, existe pelo menos um terminal arrendado especializado nesse tipo de operação. Dois portos em particular possuem concorrência interna: o Porto de Santos, que possui quatro terminais arrendados na área do porto organizado (Santos Brasil, Libra Terminais, Ecoporto e Rodrimar) e ainda o cais público, onde diversos operadores realizam essa atividade também; e o Porto do Rio de Janeiro, que possui em sua área dois terminais arrendados (Libra Terminais e Multiterminais). Somente pelo Porto de Santos passaram em média 37,6\% dos contêineres de todo o Brasil no período de 2010 a 2012. Outros portos com expressiva movimentação foram Rio Grande (7,7\%), Paranaguá $(7,4 \%)$ e Rio de Janeiro $(5,8 \%)$.

A participação dos TUPs na movimentação de contêineres vem aumentando gradativamente à medida que estes entram em operação. Em 2010 os portos organizados movimentaram 63.776 .712 toneladas $(85,5 \%)$ enquanto que os TUPs movimentaram 10.854.055 toneladas (14,5\%). Em 2012 esses números foram de 71.648 .795 toneladas $(82 \%)$ para os portos organizados e 15.688.423 toneladas para os TUPs $(18 \%)$. Note que em apenas dois anos a movimentação nesses últimos aumentou em 44\%. Os dados parciais de 2013 confirmam essa tendência de crescimento na movimentação de contêineres por parte dos terminais privativos. Além do aumento na movimentação dos terminais existentes, novos vem sendo autorizados nos últimos anos, entre os quais podem ser citados a Portonave/SC, o Porto Itapoá/SC e a Embraport/SP (iniciando suas operações em 2013).

\section{Metodologia de Análise}

Análise de Envoltória de Dados (Data Envelopment Analysis - DEA) é uma ferramenta que utiliza técnicas como a programação matemática com o objetivo de medir eficiência de unidades produtivas. Esse método de programação permite lidar com um grande número de variáveis e relações (restrições). As unidades que serão comparadas são denominadas Unidade de Tomada de Decisão (Decision Making Units - DMU). Para que se possa analisar tais unidades, elas devem possuir as mesmas entradas (denominadas inputs) e produzir as mesmas saídas (denominadas outputs).

De acordo com Cooper et al. (2006), define-se produtividade como sendo a razão existente entre aquilo que foi produzido (outputs) e aquilo que foi gasto para produzir (inputs). Desta forma, a produtividade de uma DMU pode ser definida como a razão entre a saída (output) e a entrada (input), quando se tratar de valores únicos nos dois casos. Quando existem várias entradas e 
várias saídas em análise, um índice de produtividade é definido como sendo a combinação linear das saídas dividido pela combinação linear das entradas.

A metodologia DEA permite identificar uma fronteira de eficiência onde o nível máximo de outputs obtido a partir de um determinado nível de inputs define a fronteira da tecnologia de produção. Uma pontuação, então, é fornecida para cada DMU analisada em relação a essa fronteira, permitindo assim que se realize uma avaliação de eficiência relativa para cada uma dessas unidades em relação a esta fronteira. Eficiência é um conceito relativo, que compara aquilo que foi produzido com os recursos disponíveis, com o que poderia ter sido produzido com os mesmos recursos.

Segundo a definição de Pareto-Koopmans (Charnes et al. 1985), pode-se afirmar que uma DMU é eficiente quando não for mais possível:

- Aumentar a quantidade de qualquer um dos produtos por ela gerado sem simultaneamente ser necessário reduzir a quantidade de outro produto gerado ou aumentar as quantidades dos insumos consumidos;

- Diminuir a quantidade de qualquer um dos insumos por ela consumido sem simultaneamente ser necessário aumentar a quantidade de outro insumo consumido ou diminuir as quantidades de produtos gerados.

Uma DMU tem sua eficiência avaliada calculando-se a razão entre a produtividade desta e a maior produtividade observada no conjunto das DMUs sob análise. A análise não precisa ter necessariamente uma única entrada e uma única saída. A metodologia pode levar em consideração múltiplas entradas e saídas, todavia elaborado a partir de várias abordagens de desempenho diferentes.

$$
\text { Eficiência }=\frac{\text { Produtividade atual da unidade }}{\text { Produtividade máxima que pode ser alcançada }}
$$

Uma vez que a eficiência do conjunto de DMUs esteja definida, as unidades mais eficientes podem balizar aquelas consideradas ineficientes, sendo utilizadas como referências ou benchmarks no estabelecimento de metas para se alcançar a eficiência.

Charnes et al. (1978) definiram um modelo de programação linear para medir a eficiência relativa de unidades organizacionais semelhantes, cada uma das quais utilizando múltiplos recursos (inputs) para a produção de múltiplos resultados (outputs).

Considere um conjunto de $n$ DMUs, $j=1, \ldots, n$, em que cada uma transforma $m$ inputs, $x_{i j}, i=1, \ldots, m$ para produzir $s$ outputs $, y_{r j}, r=1, \ldots, s$. Para cada DMU $j_{0}$ avaliada, é possível obter uma medida de eficiência relativa $e_{j 0}$, que é dada por:

$$
e_{j 0}=\frac{\sum_{r=1}^{s} u_{r} \cdot y_{r j 0}}{\sum_{i=1}^{m} v_{i} \cdot x_{i j 0}}
$$

Onde $x$ representa as entradas, $v$ representa os pesos de cada entrada, $y$ representa as saídas e $u$ representa os pesos de cada saída. Esses pesos são geralmente arbitrados, e essa é uma característica muito importante da metodologia DEA, uma vez que essa escolha permite que as DMUs analisadas posicionem-se da melhor maneira possível na análise de eficiência. Contudo 
essa escolha deve ser feita com muita cautela, uma vez que fatores mais importantes podem ser subestimados enquanto que outros menos importantes podem ser superestimados.

De acordo com Lins \& Meza (2000), uma das grandes vantagens da DEA é que com a análise da relação de entradas/saídas envolvidas na avaliação de desempenho das DMUs tem-se a indicação dos fatores que interferem positivamente ou negativamente sobre a eficiência dessas. Sendo assim, o uso da DEA indica quais DMUs podem ser utilizadas como benchmarking na melhoria do desempenho daquelas unidades menos eficientes. Esses benchmarks indicam o que precisa ser modificado nas entradas e saídas e como melhorá-las para transformar unidades ineficientes em unidades eficientes.

Existem quatro modelos básicos de DEA, e para utilizá-los corretamente deve-se fazer uma opção: usar um modelo orientado a outputs, no qual se obtém o máximo nível de outputs mantendo os inputs fixos, ou um modelo orientado a inputs, que visa a obter um menor uso de inputs dado o nível dos outputs.

O uso da análise envoltória de dados pode encontrar algumas barreiras. Um problema comum com a DEA é o fato de que apresenta uma baixa capacidade de ordenação das DMUs quando muitas variáveis (inputs e outputs) são consideradas para estudo e poucas DMUs estão disponíveis na amostra. Para contornar esse problema deve-se restringir o número de variáveis em questão. Senra et al. (2007) e Kirchner (2013) descrevem alguns métodos para auxiliar na decisão de seleção de variáveis, entre outros, os métodos I-O Stepwise exaustivo completo, multicritério combinatório inicial e o multicritério combinatório por cenários.

Outra maneira de se avaliar DMUs é através do índice de Malmquist, que é uma modelagem que permite a avaliação intertemporal, permitindo que se detecte evoluções (ou regressões) de produtividade quando comparados dois períodos de tempo distintos. A modelagem DEA apresentada anteriormente apresenta resultados pontuais. Outra vantagem do índice de Malmquist é a possibilidade de avaliação de DMUs que, quando analisadas sob a ótica de uma modelagem DEA básica (seja CCR ou BCC), apresentam eficiência relativa em $100 \%$. Nesta metodologia, é possível saber se houve melhora no índice de mudança de tecnologia, e não somente na mudança de eficiência. Em resumo, as etapas para o cálculo do índice de Malmquist são da seguinte forma:

1. Cálculo da distância da $\mathrm{DMU} j_{0}$ no período $t$ relativa à fronteira do período $t$.

2. Cálculo da distância da DMU $j_{0}$ no período $t+1$ relativa à fronteira do período $t$.

3. Cálculo da distância da $\mathrm{DMU} j_{0}$ no período $t$ relativa à fronteira do período $t+1$.

4. Cálculo da distância da DMU $j_{0}$ no período $t+1$ relativa à fronteira de $t+1$.

5. Cálculo do índice de eficiência técnica e índice de mudança de tecnologia.

6. Cálculo do índice de Malmquist. 


\section{Mensuração de Eficiência nos Terminais de Contêineres Brasileiros}

Em 2012 a movimentação de cargas no país superou a marca de 900 milhões de toneladas. A movimentação de contêineres foi de 87.274.908 de toneladas, ou seja $9,65 \%$ do total. Estes contêineres passaram por 22 portos organizados e 6 TUPs.

Apesar do Brasil ser notoriamente conhecido pela movimentação de granéis sólidos (61,32\% da movimentação total de mercadorias), a carga conteinerizada é de fundamental importância para o país, por se tratar do transporte de mercadorias de alto valor agregado. Geralmente são manuseados em terminais construídos para tal finalidade, e que utilizam equipamentos de alta tecnologia e mão de obra especializada.

As DMUs foram selecionadas tendo como base a movimentação de contêineres ocorrida em 2012. Uma vez selecionada, essas unidades foram estudadas também nos anos de 2011 e 2010 . A Tabela 1 mostra a movimentação de contêineres em todos os terminais do país. Pode-se observar que os 16 primeiros em destaque são responsáveis por $98,5 \%$ dessa movimentação. Em razão disso, esse foi o universo escolhido inicialmente para análise de eficiência portuária através do DEA. 
Tabela 1: Movimentação de contêineres no Brasil em 2012

\begin{tabular}{|c|c|}
\hline Porto/Terminal & Movimentação (t) \\
\hline Santos & 31.271 .803 \\
\hline Paranaguá & 6.572 .802 \\
\hline Rio Grande & 6.170 .582 \\
\hline Portonave* & 5.920 .600 \\
\hline Rio de Janeiro & 5.649 .619 \\
\hline Suape & 4.545 .651 \\
\hline Itaguaí (Sepetiba) & 4.155 .727 \\
\hline Itajaí & 3.913 .188 \\
\hline Vitoria & 3.168 .455 \\
\hline Itapoá* & 3.131 .798 \\
\hline Chibatão* & 2.996 .859 \\
\hline Salvador & 2.812 .603 \\
\hline Super Terminais* & 2.025 .026 \\
\hline Pecém* & 1.614 .035 \\
\hline São Francisco do Sul & 1.352 .785 \\
\hline Fortaleza & 707.034 \\
\hline Vila do Conde & 347.526 \\
\hline Imbituba & 263.025 \\
\hline Natal & 250.960 \\
\hline Belém & 224.310 \\
\hline Itaqui & 90.465 \\
\hline Santarém & 43.692 \\
\hline Recife & 36.536 \\
\hline São Sebastião & 4.688 \\
\hline Porto Velho & 2.822 \\
\hline Forno & 1.711 \\
\hline Macapá & 500 \\
\hline Teporti* & 106 \\
\hline TOTAL GERAL & 87.274 .908 \\
\hline $\begin{array}{l}\text { Fonte: Sistema Dese } \\
\text { ANTAQ, em } 1^{o} \text { de ju } \\
* \text { Terminais de Uso I }\end{array}$ & $\begin{array}{l}\text { enho Portuário - } \\
\text { de } 2013 . \\
\text { ativo. }\end{array}$ \\
\hline
\end{tabular}

Entretanto, os dados não podem ser trabalhados diretamente como estão colocados. No Porto de Santos existem quatro terminais arrendados especializados na movimentação de contêineres: Santos Brasil, Libra Terminais, Ecoporto Santos (antigo Tecondi) e Rodrimar, além da movimentação que ocorre no cais público, mas que não pertence a um terminal especificamente. No cais público do Porto de Santos vários operadores portuários realizam movimentação, e por essa razão não é possível analisar a eficiência da movimentação de contêineres, comparando com os demais terminais arrendados. Isso ocorre também no Porto do Rio de Janeiro, onde dentro da área do porto organizado existem dois terminais de contêineres: Libra Terminais e Multiterminais. Esses terminais concorrem entre eles na região de seu respectivo porto organizado. Faz-se necessário então considerá-los como unidades autônomas, e com isso o número de DMUs passa então para 20, descritas na Tabela 2.

Finalizada a análise dos dados referentes a 2012, passou-se a estudar os dados referentes a 2011 e 2010. Percebeu-se então um problema com dois terminais que tinham sido selecionados previamente. O TUP Porto Itapoá só começou a operar em julho de 2011. Como um dos objetivos desse estudo é acompanhar a evolução da eficiência portuária ao longo do período de 2010 a 
Tabela 2: DMUs selecionadas para análise

\begin{tabular}{|c|c|c|}
\hline DMU & Porto/Terminal & Movimentação (t) \\
\hline DMU-01 & Porto de Santos (SP) - Terminal Santos Brasil & 16.631 .118 \\
\hline DMU-02 & Porto de Paranaguá (PR) - TCP & 6.495 .634 \\
\hline DMU-03 & Porto do Rio Grande (RS) - TECON Rio Grande & 6.168 .145 \\
\hline DMU-04 & Terminal de Uso Privativo Portonave (SC) & 5.920 .600 \\
\hline DMU-05 & Porto de Santos (SP) - Libra Terminais (T-35 + T-37) & 6.657 .242 \\
\hline DMU-06 & Porto de Itaguaí (RJ) - TECON Sepetiba & 4.155 .727 \\
\hline DMU-07 & Porto de Itajaí (SC) - APM Terminais & 3.913 .188 \\
\hline DMU-08 & Porto do Rio de Janeiro (RJ) - Multiterminais & 3.593 .002 \\
\hline DMU-09 & Porto de Suape (PE) - TECON Suape & 4.545 .651 \\
\hline DMU-10 & Terminal de Uso Privativo de Itapoá (SC)* & 3.131 .798 \\
\hline DMU-11 & Porto de Vitória (ES) - TVV & 3.111 .759 \\
\hline DMU-12 & Terminal de Uso Privativo de Chibatão (AM) & 2.996 .859 \\
\hline DMU-13 & Porto de Salvador (BA) - TECON Salvador*** & 2.812 .603 \\
\hline DMU-14 & Porto de Santos (SP) - Ecoporto Santos (TECONDI) & 2.686 .425 \\
\hline DMU-15 & Porto de Santos (SP) - Rodrimar & 2.055 .115 \\
\hline DMU-16 & Terminal de Uso Privativo Super Terminais $(\mathrm{AM})^{* *}$ & 2.025 .026 \\
\hline DMU-17 & Porto do Rio de Janeiro (RJ) - Libra Terminais & 1.972 .376 \\
\hline DMU-18 & Terminal de Uso Privativo do Pecém (CE) & 1.614 .035 \\
\hline DMU-19 & Porto de São Francisco do Sul (SC) - TESC*** & 1.352 .785 \\
\hline DMU-20 & Porto de Fortaleza (CE) - Cais Público & 707.034 \\
\hline \multicolumn{3}{|c|}{$\begin{array}{l}\text { * O TUP Itapoá não foi considerado no estudo, pois começou a operar apenas em } \\
\text { junho/2011. } \\
\text { ** O TUP Super Terminais pode ser desconsiderado em função da inconsistência de } \\
\text { seus dados em } 2010 \text { e } 2011 \text {. } \\
\text { *** Inclui o respectivo cais público. } \\
\text { OBS1: Em geral os valores desta tabela não são os mesmos da Tabela } 1 \text { em razão de } \\
\text { movimentações residuais no porto. } \\
\text { OBS2: Foi desconsiderada a movimentação no cais público do Porto de Santos, em } \\
\text { razão dessa ter sido realizada por diversos operadores portuários distintos. }\end{array}$} \\
\hline
\end{tabular}

2012, foi necessária a exclusão desse terminal da análise. O TUP Super Terminais também apresentou problemas nos anos anteriores a 2012. Ao consultar a base de dados, verificaram-se inconsistências graves relativas ao tempo de operação e à taxa de ocupação de seus berços. Caso esses indicadores venham a ser considerados na avaliação será necessário descartar os dados referentes a esse terminal.

Finalmente, tem-se então 18 ou 19 DMUs (esse número será determinado mais adiante) para trabalhar-se a análise de eficiência portuária através de DEA. Note-se que a movimentação desses terminais soma 82.546.122 de toneladas, equivalente a $94,5 \%$ de toda a movimentação de contêineres do país.

Para se determinar quais variáveis serão utilizadas, toda a análise foi feita baseada em uma modelagem DEA-CCR orientada a output utilizando os valores obtidos para o ano de 2012. Essa escolha se dá devido ao fato de que o que se deseja com a análise de eficiência nesse estudo é aumentar a quantidade de contêineres movimentados ano após ano, a não ser que se perceba em algum momento que exista uma saturação de movimentação. Baseado nas estatísticas da ANTAQ sabe-se que isso não ocorre, uma vez que o histórico de movimentação de contêineres no país é crescente ao longo dos anos (com exceção do período da crise financeira internacional em 2008).

Foi escolhida como output para esse estudo a quantidade de contêineres movimentada. No meio portuário todos os portos e terminais exibem suas estatísticas de recordes de movimentação. O grande objetivo de um terminal é movimentar carga, pois quanto mais carga for movimentada, maior é o lu- 
cro desse terminal. Devido a essa importância, nada mais natural que adotar esse indicador como output, e mais, como metas finalísticas para aumento de eficiência portuária.

Quanto aos inputs um indicador muito utilizado é a área do terminal. Essa variável traduz a capacidade de armazenamento de contêineres, bem como maior agilidade para manuseio de cargas. Terminais que possuem grandes áreas disponíveis conseguem dinamizar melhor sua logística interna, o que influi positivamente em sua produtividade, melhorando assim sua eficiência. Dificilmente esse dado muda em um ano, pois alterações de áreas, sejam em terminais arrendados ou em terminais de uso privativo, precedem de projetos, análises econômico-financeiras e autorizações do órgão regulador, o que demanda bastante tempo.

Outro indicador muito utilizado é o comprimento total do cais. Berços de atracação maiores permitem a operação de navios maiores. Quando se operam navios maiores, a produtividade do terminal aumenta. Além disso, berços maiores permitem a instalação de um maior número de equipamentos (portêineres e MHCs por exemplo), bem como permitem maior mobilidade destes, o que também influencia positivamente a produtividade. Esse indicador também tem uma baixa variação com o passar do tempo e não é coletado eletronicamente pela agência reguladora, sendo esta informada diretamente pelos terminais.

Menos utilizado, mas ainda presente em alguns trabalhos sobre o tema, a profundidade do terminal ou do canal de acesso também pode ser uma variável pertinente. Nos últimos anos o governo federal investiu muito nas dragagens dos principais portos do país. Atualmente esse investimento já mostra resultados, pois navios de maior porte conseguem atracar onde antes era impossível. Profundidades maiores permitem a atracação de navios maiores e mais carregados, além do que a capacidade de um navio aumenta significativamente quando este pode calar mais. Portanto, quanto maior a profundidade, maior a possibilidade de contêineres movimentados.

Um indicador muito bem relacionado com a quantidade de contêineres movimentada em um terminal é o número de atracações. Obviamente, quanto mais navios atracarem em um terminal, maior será sua movimentação de contêineres. Neste estudo, foi considerado para cada terminal o somatório do número de atracações ocorridas no período de um ano. Uma grande importância desse indicador é que ele mostra quando um terminal possui uma hinterlân$\mathrm{dia}^{4}$ significativa.

Outro dado coletado mensalmente pela ANTAQ é a consignação média (Consig) do terminal, que também influencia fortemente no output que está em estudo. Esse indicador é definido como sendo o número de contêineres movimentados por atracação em um período de tempo específico, ou seja,

$$
\text { Consig }_{a}=\frac{\sum_{i=1}^{n} n \operatorname{cont}_{a i}}{n_{a}}
$$

em que Consiga é a consignação média do terminal no período $a$, ncont $t_{a} i$ é o número de contêineres movimentados na atracação $i$ do período $a$ e $n_{a}$ é o número total de atracações ocorridas no terminal no período $a$. A consignação média dos navios que atracam em um terminal pode ser obtida para

\footnotetext{
${ }^{4}$ Hinterlândia é a área de influência de um porto que, por concentrar significativa atividade econômica, pode engendrar uma rede urbana de centros urbanos menores.
} 
várias unidades temporais. Terminais que apresentam um alto valor para a consignação média são aqueles ditos como de fim de linha como por exemplo os terminais de uso privativo de Chibatão e Super Terminais. A combinação da consignação média e número de atracações influenciam significativamente a quantidade de contêineres movimentados nos terminais.

Um primeiro indicador de produtividade que pode ser considerado é o tempo médio de operação (TMop). Este é definido como sendo o tempo decorrido para realizar toda a operação de carga e descarga de uma atracação, ou seja,

$$
\operatorname{TMop}_{a}=\frac{\sum_{i=1}^{n} \operatorname{Top}_{a i}}{n_{a}}
$$

em que TMop $p_{a}$ é o tempo médio de operação do terminal no período $a$, Top $p_{a i}$ é o tempo total de operação da atracação $i$ do período $a$ e $n_{a}$ é o número total de atracações ocorridas no terminal no período $a$. Note-se que esse é um indicador, a princípio, inversamente proporcional à quantidade movimentada de contêineres de um terminal, e isso deve ser levado em consideração na análise. Quanto mais tempo gasto na operação de um navio, menos atracações podem ser realizadas no restante do período em análise. O contrário também é verdadeiro, ou seja, quanto menos tempo gasto na operação de um navio, em tese, mais navios podem atracar no restante do período em análise. Foi considerado para análise o inverso do tempo médio de operação anual por terminal.

Outro indicador calculado é a taxa de ocupação dos berços (Tbercos). Com todas essas informações pode-se calcular a taxa de ocupação dos berços de um terminal em uma unidade de tempo específica:

$$
\operatorname{Tbercos}_{a}=\frac{\sum_{i=1}^{n} \text { natrac }_{a i} \cdot \bar{t} a_{a i}}{\sum_{i=1}^{n} n a t_{a i}}
$$

em que $\operatorname{Tbercos}_{a}$ é a taxa de ocupação dos berços do terminal no período $a$, $n_{\text {natrac }} c_{a i}$ é o número de atracações ocorridas no berço $i$ no período $a, t \bar{a}_{a i}$ é o tempo médio atracado por navio no berço $i$ no período $a$ e $n$ é o número de berços do terminal. Nesse estudo foi considerado o período de tempo anual e os passos do cálculo da taxa de ocupação dos berços de um terminal é ilustrado na Figura 1, considerando como exemplo o terminal arrendado Santos Brasil localizado na área do Porto de Santos.

Note que pode-se falar de atracações realizadas em um ano no Porto de Santos, por exemplo. Dentro do porto pode-se separar essas atracações para cada um dos terminais arrendados (Santos Brasil, Libra Terminais, Rodrimar, Ecoporto Santos) e o cais público (conhecido como Margem Direita); podese ainda especificar aonde foi feita a atracação em cada um desses terminais (em qual berço) e contabilizar a soma de atracações nesse nível, por exemplo, na Santos Brasil existem quatro berços de atracação (SSZ0811, SSZ0812, SSZ0813 e SSZ0816).

O último indicador utilizado nessa análise, mas com certeza extremamente importante quando o assunto é produtividade, é a prancha média de operação. A prancha média é definida como a quantidade de contêineres movimentados por hora, ou seja,

$$
\operatorname{Prancha}_{a}=\frac{\sum_{i=1}^{n} \frac{n \operatorname{cont}_{a i}}{\text { Top }_{a i}}}{n_{a}}
$$




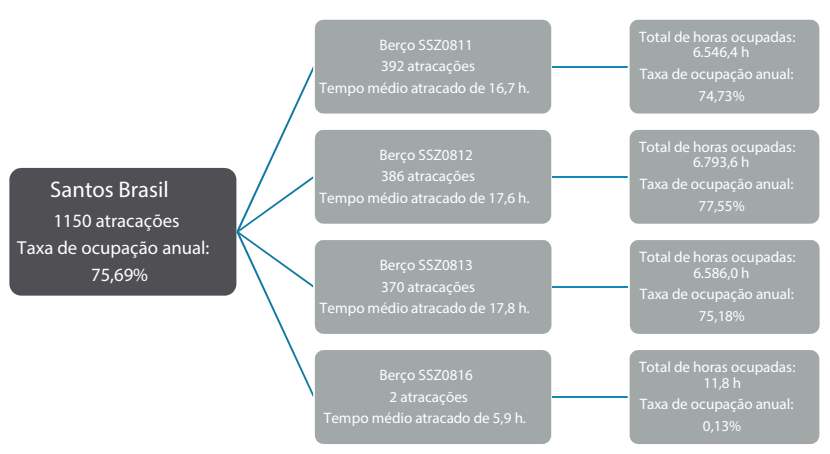

Figura 1: Cálculo da taxa de ocupação dos berços do terminal Santos Brasil

em que Prancha $a_{a}$ é a prancha média do terminal no período $a, n c o n t_{a i}$ é o número de contêineres movimentados na atracação $i$ do período $a$, Top $p_{a i}$ é o tempo total de operação da atracação $i$ do período $a$ e $n_{a}$ é o número total de atracações ocorridas no terminal no período $a$.

Este indicador talvez seja um dos mais importantes nesse tema, uma vez que diversas inferências podem ser atribuídas a ele. Considere, por exemplo, portêineres e MHCs, equipamentos relevantes para movimentação de contêineres na beira do cais. O primeiro consegue atingir a movimentação de até 45 contêineres/hora enquanto que o segundo consegue alcançar até 30 contêineres/hora. O número de equipamentos instalados nos terminais especializados afeta diretamente a capacidade total de operação do terminal. Terminais não especializados geralmente possuem restrição para atracação de navios, pois só podem receber aqueles que possuem equipamentos de bordo, que possuem uma produtividade muito baixa.

Combinado com os equipamentos de beira de cais, existem ainda outros equipamentos que influenciam diretamente a capacidade de movimentação de um terminal. Os contêineres precisam estar disponíveis rapidamente (no caso de embarque) ou então precisam desocupar a área operacional (no caso de desembarque) o mais rápido possível. Para esses fins, citam-se: $R T G$, reach stackers, top-lifts, straddle carriers, runners, empty container handlers e terminal tractors.

Outra inferência que pode ser feita através do indicador prancha média é o número de colaboradores especializados do terminal. É de se esperar que para operar todos os equipamentos citados anteriormente seja necessária uma mão de obra mínima.

Para escolha dessas variáveis, serão utilizados os indicadores físicos e operacionais referentes ao ano de 2012. Para o output é a quantidade de contêineres movimentada no terminal (QUANT). Para os inputs deve-se escolher variáveis dentre: área do terminal (AREA), comprimento total de cais (CCAIS), profundidade do terminal ou do canal de acesso (PROF), quantidade de atracações (NATRAC), consignação média (CONSIG), inverso do tempo médio de operação (ITOP), taxa de ocupação dos berços (BERÇOS) e prancha média (PRANCHA).

Pelo Método I-O Stepwise exaustivo completo, os inputs selecionados são: número de atracações, área do terminal, consignação média e prancha média. 
Pelo Método Multicritério Combinatório Inicial, os inputs selecionados são: número de atracações, prancha média, consignação média e taxa de ocupação dos berços. E pelo Método Multicritério Combinatório por Cenários, os inputs selecionados são: número de atracações, prancha média, consignação média, taxa de ocupação dos berços, profundidade do terminal e comprimento total de cais do terminal.

Outra análise importante que deve ser considerada é a correlação entre as variáveis de input e a variável de output. Os valores dessas correlações são dados na Tabela 3.

Observe que as maiores correlações observadas com relação ao output escolhido são, nessa ordem (em módulo): número de atracações, prancha média, área do terminal, consignação média, taxa de ocupação dos berços, comprimento total de cais do terminal, profundidade do canal e o inverso do tempo médio de operação.

A Figura 2 resume os resultados descritos até então. Os indicadores número de atracações, prancha média e consignação média aparecem nos três métodos estudados, e não resta a menor dúvida que devam ser utilizados para se calcular a eficiência de um terminal de contêineres. Resta determinar se é necessária a inclusão de um ou mais indicadores com base nos resultados obtidos até então.

Do ponto de vista apenas de modelagem numérica, pode-se perceber que o resultado, em termos de eficiência média dos terminais, é muito maior quando se considera a inclusão da área do terminal. Nota-se também que os valores dessas eficiências médias são muito próximos quando consideramos a inclusão da taxa de ocupação dos berços apenas comparando com a inclusão desta, da profundidade do terminal e do comprimento total de cais do terminal. Em ambos os casos, os valores obtidos são $8,5 \%$ menores do que aquele obtido com a inclusão da área do terminal. Certamente, do ponto de vista matemático, a variável área do terminal contribui muito mais para o cálculo da eficiência do terminal do que as demais. Além disso, perceba que a correlação com a quantidade de contêineres movimentada é maior que quaisquer outras variáveis em dúvida de utilização nesse ponto.

Do ponto de vista da metodologia DEA, não convém adicionar muitas variáveis com um número reduzido de DMUs para análise, pois além de poder acarretar na existência de muitas DMUs na fronteira de eficiência (baixa discricionariedade), pode-se observar que algumas variáveis não terão participação alguma com sua inclusão no aumento de eficiência. Parece ser muito coerente utilizar-se da regra descrita no método multicritério combinatório inicial, que sugere a interrupção do acréscimo de variáveis quando o número de DMUs em estudo não for superior ao quíntuplo do número de variáveis envolvidas (inputs e outputs).

Finalmente, chega-se a uma conclusão sobre quais indicadores devem ser considerados na análise de eficiência dos terminais de contêineres através de DEA: como inputs serão utilizados número de atracações, prancha média, consignação média e área do terminal. Como output já foi definido o indicador quantidade de contêineres movimentada, sendo esse um objetivo a ser sempre maximizado quando se falar de aumento de eficiência.

A partir desse ponto, uma vez que se têm as variáveis definidas, far-se-á a análise através de uma das duas modelagens: DEA-CCR orientado a output ou DEA-BCC orientado a output. As próximas tabelas mostram o resultado ob- 
Tabela 3: Matriz de correlações entre as variáveis em estudo, em 2012

\begin{tabular}{|c|c|c|c|c|c|c|c|c|c|}
\hline NATRAC & CONSIG & CCAIS & AREA & ITOP & BERCOS & PRANCHA & PROF & QUANT & \\
\hline NATRAC & 1,0000 & & & & & & & & \\
\hline CONSIG & 0,1919 & 1,0000 & & & & & & & \\
\hline CCAIS & 0,2608 & 0,0366 & 1,0000 & & & & & & \\
\hline AREA & 0,5916 & 0,4241 & 0,1610 & 1,0000 & & & & & \\
\hline ITOP & 0,2354 & $-0,5276$ & 0,1912 & $-0,2218$ & 1,0000 & & & & \\
\hline BERCOS & 0,4780 & 0,1273 & $-0,2103$ & 0,3827 & 0,2087 & 1,0000 & & & \\
\hline PRANCHA & 0,6406 & 0,3860 & 0,3956 & 0,2745 & 0,5065 & 0,4354 & 1,0000 & & \\
\hline PROF & $-0,0463$ & 0,1040 & $-0,4780$ & 0,1568 & 0,0703 & 0,3853 & $-0,0407$ & 1,0000 & \\
\hline QUANT & 0,8994 & 0,5428 & 0,3287 & 0,6562 & 0,0141 & 0,4452 & 0,7305 & $-0,1000$ & 1,0000 \\
\hline
\end{tabular}



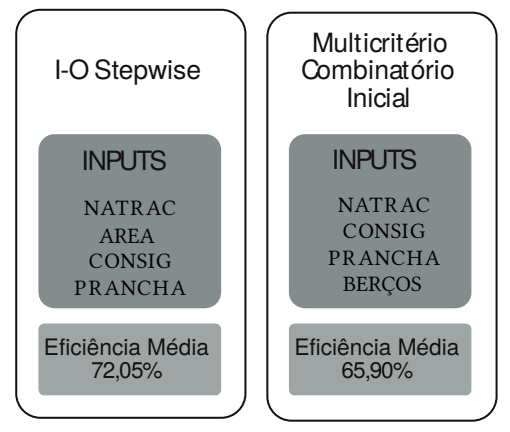

Multicritério Combinatório por Cenários
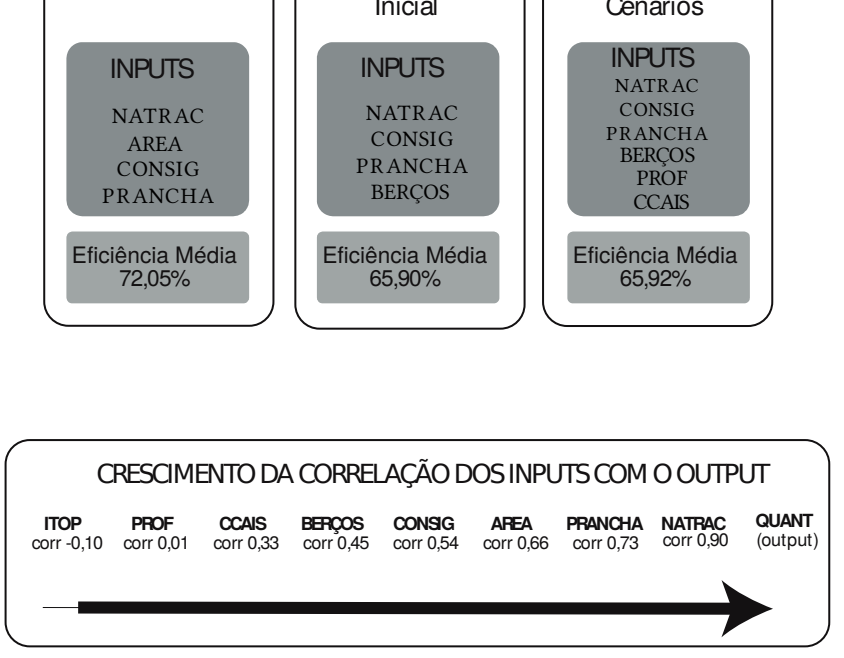

Figura 2: Resultados obtidos para escolha dos indicadores a serem considerados para medição da eficiência nos terminais movimentadores de contêineres

tido para todos os anos em análise (2010, 2011 e 2012), nas duas modelagens supracitadas.

Uma percepção importante aqui é o baixo poder discriminatório entre as eficiências que é notório no modelo BCC. Para fins de análise de eficiência, e ainda a evolução dessas eficiências ao longo do tempo, percebe-se claramente que o modelo CCR é mais adequado ao propósito desse estudo.

O gráfico da Figura 3 ilustra o comportamento das eficiências calculadas de 2010 a 2012, ordenadas de forma decrescente de eficiências segundo o ano mais recente da análise. Interessante notar que das nove DMUs que tiveram eficiência acima de $80 \%$ em 2012, três se mantiveram em $100 \%$ por todos os anos e cinco apresentaram evolução de eficiência ao longo do período em estudo.

Neste estudo podemos destacar dois grupos de terminais. O primeiro grupo é composto pelos terminais eficientes, que foram os mesmos durante os 3 períodos de estudo:

- Tecon Santos Brasil (DMU-01), terminal arrendado localizado no Porto de Santos, especializado na operação de contêineres, e o maior do país em termos de quantidade movimentada.

- Libra Terminais (DMU-05), cuja operação engloba os terminais T-35 e T-37, ambos dentro da área do porto organizado de Santos.

- Terminal de Uso Privativo de Chibatão (DMU-12), localizado em Manaus, é um dos principais terminais do norte do país.

O segundo grupo importante para análise aqui é composto pelos terminais que, ao observar o ano de 2012, alcançaram um índice de eficiência acima de $80 \%$. Destes terminais, cinco apresentam crescimento sistêmico na medida de eficiência: 
Tabela 4: Eficiência dos terminais de contêineres de 2010 a 2012

\begin{tabular}{lrrrlrrr}
\hline & \multicolumn{3}{c}{ Modelo DEA-CCR } & & \multicolumn{3}{c}{ Modelo DEA-BCC } \\
& $\mathbf{2 0 1 0}$ & \multicolumn{1}{c}{$\mathbf{2 0 1 1}$} & \multicolumn{1}{c}{$\mathbf{2 0 1 2}$} & & $\mathbf{2 0 1 0}$ & $\mathbf{2 0 1 1}$ & \multicolumn{1}{c}{$\mathbf{2 0 1 2}$} \\
\hline DMU-01 & 100,00 & 100,00 & 100,00 & DMU-01 & 100,00 & 100,00 & 100,00 \\
DMU-02 & 73,36 & 76,82 & 83,64 & DMU-02 & 100,00 & 91,52 & 100,00 \\
DMU-03 & 87,03 & 76,18 & 76,51 & DMU-03 & 100,00 & 100,00 & 95,97 \\
DMU-04 & 60,25 & 74,17 & 82,27 & DMU-04 & 80,15 & 81,26 & 100,00 \\
DMU-05 & 100,00 & 100,00 & 100,00 & DMU-05 & 100,00 & 100,00 & 100,00 \\
DMU-06 & 43,07 & 41,66 & 55,88 & DMU-06 & 100,00 & 100,00 & 68,24 \\
DMU-07 & 68,50 & 79,37 & 89,63 & DMU-07 & 79,29 & 88,55 & 95,53 \\
DMU-08 & 37,87 & 48,07 & 54,65 & DMU-08 & 99,96 & 100,00 & 86,50 \\
DMU-09 & 60,46 & 84,12 & 46,25 & DMU-09 & 91,23 & 100,00 & 77,17 \\
DMU-11 & 73,36 & 83,17 & 82,63 & DMU-11 & 90,92 & 98,12 & 100,00 \\
DMU-12 & 100,00 & 100,00 & 100,00 & DMU-12 & 100,00 & 100,00 & 100,00 \\
DMU-13 & 60,19 & 51,99 & 65,09 & DMU-13 & 100,00 & 94,47 & 100,00 \\
DMU-14 & 93,59 & 95,31 & 82,78 & DMU-14 & 100,00 & 100,00 & 92,41 \\
DMU-15 & 60,51 & 61,50 & 58,89 & DMU-15 & 100,00 & 100,00 & 100,00 \\
DMU-16 & 60,22 & 87,72 & 90,29 & DMU-16 & 100,00 & 100,00 & 100,00 \\
DMU-17 & 41,60 & 45,61 & 48,52 & DMU-17 & 100,00 & 100,00 & 100,00 \\
DMU-18 & 41,13 & 44,70 & 37,98 & DMU-18 & 100,00 & 100,00 & 100,00 \\
DMU-19 & 52,13 & 56,51 & 42,36 & DMU-19 & 100,00 & 100,00 & 100,00 \\
DMU-20 & 41,74 & 35,83 & 33,63 & DMU-20 & 100,00 & 100,00 & 100,00 \\
\hline EFF & 66,05 & 70,67 & 70,05 & EFF & 96,92 & 97,57 & 95,57 \\
\hline
\end{tabular}




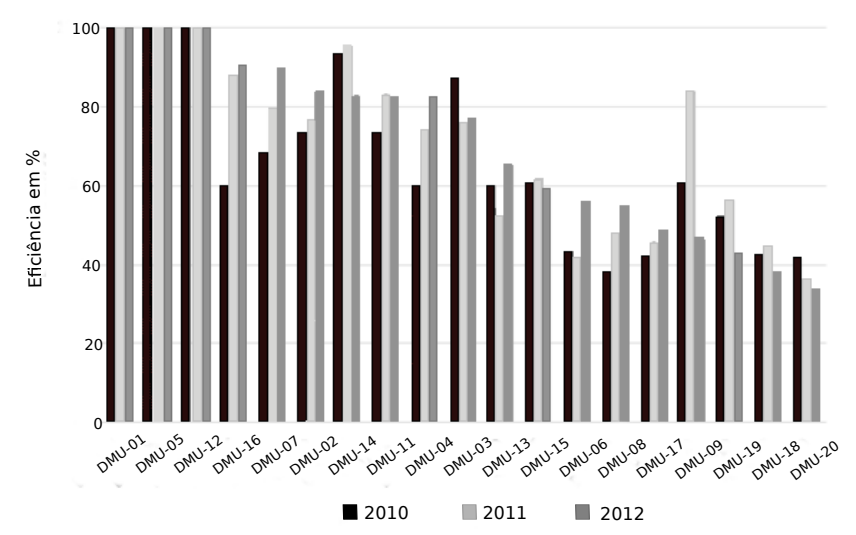

Figura 3: Eficiência das DMUs de 2010 a 2012 segundo DEA-CCR orientado a output

- Terminal de Uso Privativo Super Terminais (DMU-16), localizado em Manaus, é um dos principais terminais do norte do país, vizinho ao TUP Chibatão, teve uma evolução de sua eficiência relativa de $60,2 \%$ para $90,3 \%$.

- APM Terminais (DMU-07), terminal arrendado do Porto de Itajaí, é o único operador de contêineres deste último, atuando tanto no cais preferencial quanto no cais público, teve uma evolução de sua eficiência relativa de $68,5 \%$ para $89,6 \%$.

- TCP (DMU-02), terminal arrendado do Porto de Paranaguá. É o segundo terminal do país em questão de movimentação de contêineres. Mostrou uma evolução de sua eficiência relativa de $73,4 \%$ para $83,6 \%$.

- TVV (DMU-11), terminal arrendado do Porto de Vitória, apresentou uma evolução de sua eficiência relativa de $73,4 \%$ para $82,6 \%$, sendo esse último valor ligeiramente menor do que o apresentado em 2011, quando atingiu $83,2 \%$.

- Terminal de Uso Privativo da Portonave (DMU-04), localizado em Santa Catarina, é um terminal que entrou em operação recentemente e já mostra uma melhoria significativa em sua eficiência segundo os dados apresentados, evoluindo no período de $60,3 \%$ para $82,3 \%$.

Para uma análise da evolução das eficiências utiliza-se o índice de Malmquist (IM) que tem por objetivo avaliar os índices de produtividade em diferentes datas, além de decompor esses valores em sub-índices denominados índice de eficiência técnica (IE) e índice de mudança de tecnologia (IT). Analisando esses valores, pode-se tirar conclusões acerca das causas que contribuem para um aumento (ou diminuição) da eficiência total de uma DMU. Na teoria, o índice de Malmquist também é conhecido como Fator de Produtividade Total (PFT).

A análise através do índice de Malmquist preenche um "vazio" deixado pela análise de eficiência através de DEA-CCR ou ainda de DEA-BCC. Nesta metodologia é possível identificar progressão (ou regressão) na produtividade 
de DMUs definidas como eficientes em ambos os períodos de um estudo. A Tabela 5 fornece o valor desses índices para todas as situações possíveis de análise no período de 2010 a 2012.

Observe que o terminal Santos Brasil (DMU-01) sempre manteve o índice de mudança de eficiência técnica igual a unidade, o que é coerente com o resultado obtido através da metodologia DEA-CCR, onde em todos os períodos esse terminal permaneceu com $100 \%$ de eficiência. Todavia foi detectado uma leve piora nos indicadores de mudança de tecnologia.

De outro ponto de vista, a Libra Terminais - Santos (DMU-05) também manteve a unidade no índice de mudança de eficiência técnica, o que corrobora também com o resultado apresentado na metodologia DEA-CCR. No caso da Libra, além da eficiência relativa se manter em $100 \%$ em todos os anos, houve um incremento no índice de mudança de tecnologia, o que significa que os insumos no período $t+1$ estão sendo melhor aproveitados.

Este é o significado do índice de mudança de eficiência. Quando o valor é superior à unidade, isso significa que comparando os dados do período $t+1$ com o período $t$ (período $t$ como referência), a DMU aproximou-se mais da fronteira de eficiência. Já o índice de mudança de tecnologia mostra que a DMU está aproveitando de uma melhor maneira seus insumos para produzir o output.

Quando se compara 2011 com 2010, percebe-se que houve uma melhora no IM dos terminais em sua grande maioria e o valor médio da amostra foi 1,1028. Isso já não ocorre quando se compara 2012 com 2011. Neste caso, apenas seis terminais apresentaram uma melhoria nesse índice, e o IM médio ficou em 0,9283 . Essa situação fica muito clara quando se comparam os dados no gráfico da Figura 4. 
Tabela 5: Decomposição do índice de Malmquist nos períodos de 2010 a 2012

\begin{tabular}{|c|c|c|c|c|c|c|c|c|c|}
\hline & \multicolumn{3}{|c|}{2010 e 2011} & \multicolumn{3}{|c|}{2011 e 2012} & \multicolumn{3}{|c|}{2010 e 2012} \\
\hline & IM & IE & IT & IM & IE & IT & IM & IE & IT \\
\hline DMU-01 & 0,9902 & 1,0000 & 0,9902 & 0,8491 & 1,0000 & 0,8491 & 0,8315 & 1,0000 & 0,8315 \\
\hline DMU-02 & 1,0067 & $\overline{1,0472}$ & 0,9614 & 0,8713 & $\overline{1,0887}$ & 0,8003 & 0,8884 & $\overline{1,1401}$ & 0,7792 \\
\hline DMU-03 & 0,9306 & 0,8753 & 1,0632 & 0,8929 & 1,0043 & 0,8890 & 0,7890 & 0,8791 & 0,8975 \\
\hline DMU-04 & 1,3017 & 1,2309 & 1,0575 & 1,0667 & 1,1093 & 0,9616 & 1,4235 & 1,3655 & 1,0425 \\
\hline DMU-05 & 1,0242 & 1,0000 & 1,0242 & 0,8380 & 1,0000 & 0,8380 & 0,8426 & 1,0000 & 0,8426 \\
\hline DMU-06 & 1,0286 & 0,9674 & 1,0632 & 1,2503 & $\frac{1,3411}{1,34}$ & 0,9323 & 1,3411 & 1,2975 & 1,0336 \\
\hline DMU-07 & 1,1954 & 1,1588 & 1,0316 & 1,1876 & 1,1292 & 1,0518 & 1,3840 & 1,3085 & 1,0577 \\
\hline DMU-08 & 1,3627 & 1,2692 & 1,0737 & 1,1083 & 1,1369 & 0,9748 & 1,4819 & 1,4429 & 1,0270 \\
\hline DMU-09 & 1,3680 & 1,3914 & 0,9832 & 0,4141 & 0,5498 & 0,7532 & 0,6618 & 0,7650 & 0,8652 \\
\hline DMU-11 & 1,1438 & 1,1338 & 1,0089 & 1,0900 & 0,9935 & 1,0972 & 1,2587 & 1,1264 & 1,1175 \\
\hline DMU-12 & 0,9251 & 1,0000 & 0,9251 & 0,9905 & 1,0000 & 0,9905 & 0,9276 & 1,0000 & 0,9276 \\
\hline DMU-13 & 0,9258 & 0,8637 & 1,0719 & 1,0362 & $\overline{1,2520}$ & 0,8276 & 0,9594 & $\overline{1,0813}$ & 0,8872 \\
\hline DMU-14 & 1,0483 & 1,0184 & 1,0293 & 0,8961 & 0,8685 & 1,0318 & 0,9386 & 0,8845 & 1,0612 \\
\hline DMU-15 & 1,0562 & 1,0165 & 1,0391 & 0,8007 & 0,9574 & 0,8363 & 0,7847 & 0,9732 & 0,8063 \\
\hline DMU-16 & 1,4843 & 1,4568 & 1,0189 & 0,9898 & 1,0293 & 0,9615 & 1,4814 & 1,4995 & 0,9879 \\
\hline DMU-17 & 1,1529 & 1,0964 & 1,0516 & 0,9478 & 1,0637 & 0,8911 & 1,1439 & 1,1662 & 0,9809 \\
\hline DMU-18 & 1,0507 & 1,0867 & 0,9668 & 0,6914 & 0,8497 & 0,8137 & 0,7733 & 0,9234 & 0,8375 \\
\hline DMU-19 & 1,0832 & 1,0841 & 0,9991 & 0,7492 & 0,7496 & 0,9994 & 0,9058 & 0,8127 & 1,1147 \\
\hline DMU-20 & 0,8741 & 0,8583 & 1,0184 & 0,9684 & 0,9386 & 1,0318 & 0,8474 & 0,8056 & 1,0518 \\
\hline
\end{tabular}


Figura 4: Decomposição do índice de Malmquist nos períodos de 2010 a 2012

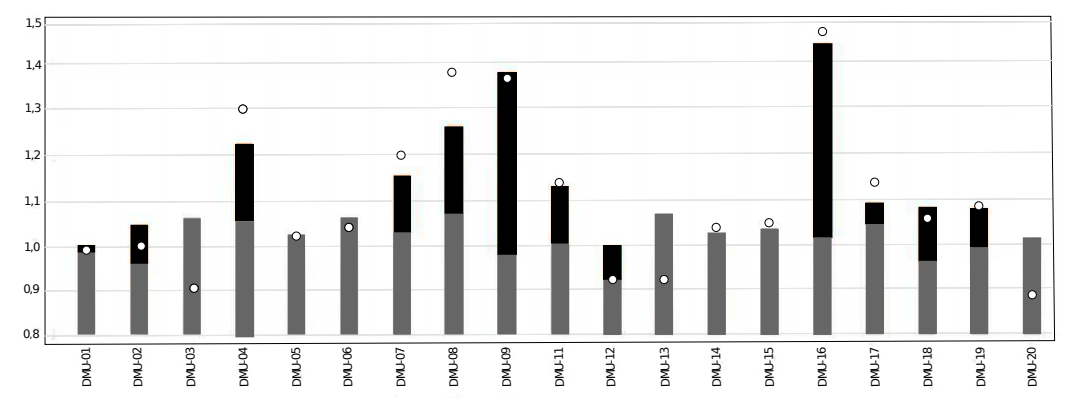

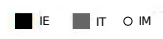
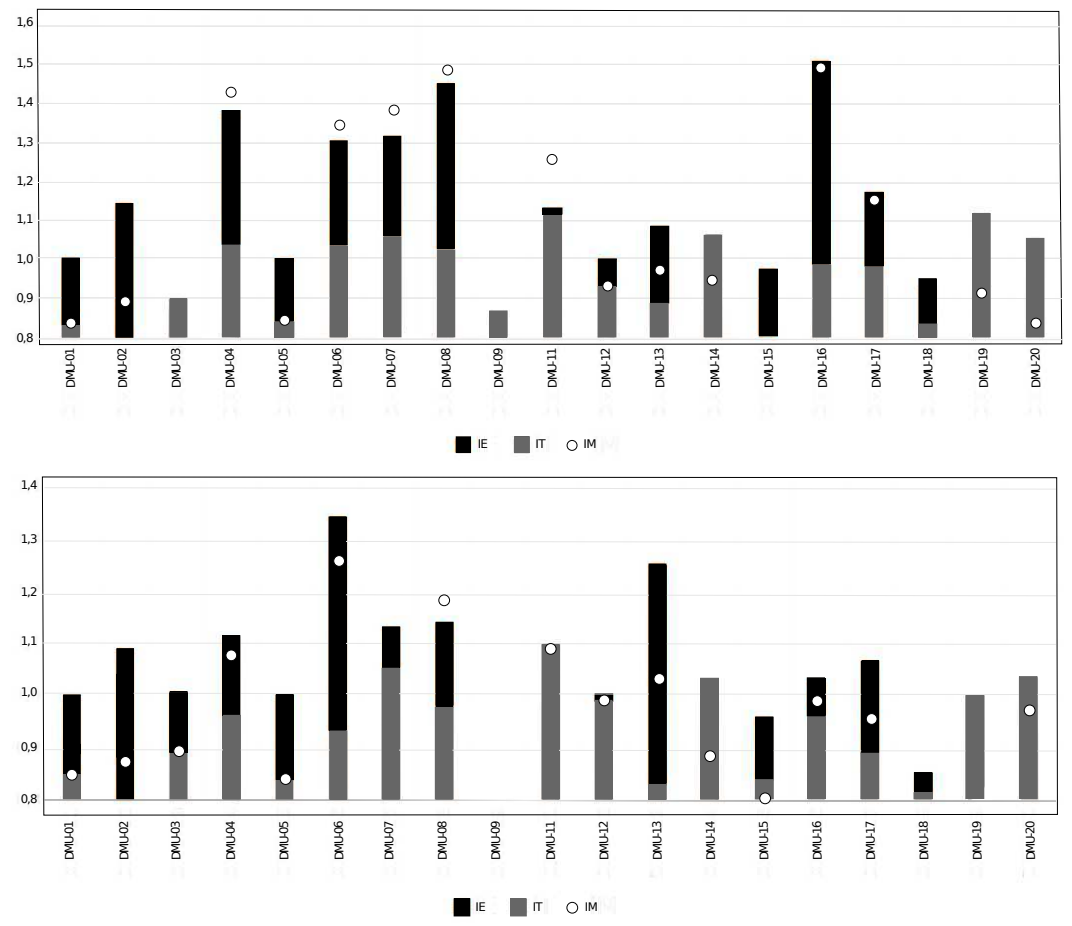

\section{Conclusões}

A análise de eficiência deve ser pautada em alguns pilares fundamentais. Especificamente no caso de terminais portuários, deve-se primeiramente decidir o tipo de carga que será analisada. A operação de um terminal de contêineres é diferente da operação de um terminal de granel líquido ou de um terminal que movimenta minério de ferro, por exemplo. O porte dos navios é diferente, a infra-estrutura é diferente, os tempos operacionais são diferentes.

A escolha dos indicadores que serão utilizados na análise também é muito importante. Não se deve escolher uma quantidade excessiva de variáveis, pois esse tipo de escolha faz com que muitas DMUs fiquem localizadas na fronteira de eficiência, enfraquecendo assim o poder discriminatório da metodologia. 
Neste estudo foram considerados quatro inputs e um output e os resultados no modelo CCR demonstraram que apenas três DMUs foram consideradas como eficientes.

Neste estudo, em primeiro lugar, limitou-se a natureza da carga a ser movimentada nos terminais: carga conteinerizada. Não foram diretamente utilizados os dados dos portos como um todo, o que diminuiu um pouco a pressão dos números do Porto de Santos em relação aos demais portos. Por se tratar da análise de terminais especializados, optou-se por separá-los, e com isso, o Porto de Santos ficou subdividido em quatro terminais arrendados (Tecon Santos Brasil, Libra Terminais, Rodrimar e Ecoporto Santos) e o Porto do Rio de Janeiro em dois (Libra Terminais e Multiterminais). Em segundo lugar, os valores das eficiências encontrados nesta modelagem foram bem coerentes. Considerando o valor médio das eficiências nos três anos de análise, na fronteira de eficiência permaneceram dois terminais de grande porte (Tecon Santos Brasil e Libra Terminais - Santos) e um terminal de menor porte (TUP Chibatão). Os terminais menos eficientes na média, segundo a modelagem CCR, foram o Porto de Fortaleza, o TUP Pecém e a Libra Terminais - Rio de Janeiro. Os três terminais realmente estão entre os de menor escala de movimentação, mas é importante observar os resultados dos terminais Multiterminais e Tecon Sepetiba. Ambos os terminais possuem uma escala de movimentação de contêineres bem maior, mas tiveram resultados médios de eficiência muito semelhantes aos piores encontrados na pesquisa.

Portanto, a modelagem CCR apresentou excelentes resultados com as variáveis escolhidas para análise neste artigo. Os valores de eficiências obtidos para os anos de 2010, 2011 e 2012 mostraram-se bastante coerentes. É importante destacar aqui o valor de se ter um bom histórico de dados. Ao analisar a eficiência dos terminais, incorporando os próximos anos, será possível fazer diversas comparações, com diversas variáveis distintas, e optar por um conjunto de indicadores que reflita a situação dos terminais de modo ainda mais preciso.

A análise intertemporal através do índice de Malmquist mostra a evolução da produtividade de um terminal de contêineres. Neste estudo foram feitas três análises: 2010/2011, 2011/2012 e 2010/2012 (sendo sempre o mais antigo como referência inicial), todas orientadas a outputs.

A primeira conclusão que se pode obter é que o fato de um terminal se manter na fronteira de eficiência nos três anos quando foi aplicada a metodologia DEA - CCR não significa necessariamente que houve uma manutenção de seus índices de produtividade. Na verdade, a diferença aparece na decomposição do índice de Malmquist em índice de mudança de eficiência e índice de mudança de tecnologia.

Como visto anteriormente, três terminais mantiveram-se na fronteira de eficiência durante 2010, 2011 e 2012. Analisando o índice de mudança de tecnologia destes três terminais, observamos que no caso do Tecon Santos Brasil esse índice caiu, apresentando uma piora nesse critério. Isso significa que, apesar de se manter na fronteira de eficiência, os inputs estão sendo utilizados de uma maneira menos eficiente que no período anterior. A Libra Terminais Santos apresentou uma melhora no primeiro período $(2010 / 2011)$ e uma piora no segundo $(2011 / 2012)$ e o TUP Chibatão mostrou piora nos dois períodos analisados.

Cinco terminais apresentaram melhoras sucessivas nos períodos analisados: TUP Portonave/SC, Tecon Sepetiba/RJ, APM Terminais/SC, Multitermi- 
nais/RJ e TVV/ES. Quatro terminais apresentaram quedas sucessivas na série estudada: Tecon Santos Brasil, Tecon Rio Grande, TUP Chibatão e o Porto de Fortaleza.

De posse desses índices, a ANTAQ poderá estipular algumas metas que farão com que os terminais mostrem uma evolução de produtividade. Por exemplo, considere o caso do TUP Pecém. Caso a movimentação de contêineres em 2012 fosse de 135.000 toneladas ao invés das 92.904 toneladas registradas, e todos os demais terminais mantivessem seus resultados originais, a eficiência não aumentaria (manteria 44,7\%), mas o índice de Malmquist teria uma alteração significativa (aumentaria de 0,6914 para 1,0047). Este é um número bem mais plausível como meta do que as quase 245.000 toneladas calculadas como ineficiência direta do modelo CCR. Para a Libra Terminais - Santos, por exemplo, a meta de movimentação de contêineres que tornaria o índice de Malmquist maior que a unidade (aumentaria de 0,8380 para 1,0015) seria 550.000 toneladas.

\section{Referências Bibliográficas}

Banker, R., Charnes, A. \& Cooper, W. W. (1984), 'Some models for estimating technical and scale inefficiencies in data envelopment analysis', Management Science 30(9), 1078-1092.

Charnes, A., Cooper, W. W., Lewin, A. Y. \& Seiford, L. (1985), Data envelopment analysis, 2 edn, Boston, KAP.

Charnes, A., Cooper, W. W. \& Rhodes, E. (1978), 'Measuring the efficiency of decision making units', European Journal of Operational Research 2(6), 429444 .

Cooper, W. W., Seiford, L. M. \& Tone, K. (2006), Introduction to data envelopment analysis and its uses with DEA-solver software and references.

Coutinho, P., Oliveira, A. R. d., Carvalho, A. X. Y. d., Britto, P. A. P. d., Lustosa, P., Camargo, R. S. d. \& Lucas, V. (2012), Comparativo das estruturas de custos e avaliação de projetos/investimentos entre terminais portuários de uso público e terminais portuários de uso privativo misto, Technical report, CERME-UnB.

Fernandes, R. L. (2010), Avaliação dos terminais que movimentam contêineres no Brasil através da análise envoltória de dados. Rio de Janeiro, COPPE/UFRJ.

Fontes, O. H. P. M. (2006), Avaliação da eficiência portuária através de uma modelagem DEA. Niterói, UFF.

Kirchner, L. H. C. (2013), Avaliação da eficiência dos terminais de contêineres através da análise envoltória de dados e do índice de Malmquist. Brasília, 96 fls. Dissertação de Mestrado, UnB, Centro de Estudos e Regulação de Mercados - CERME - REGEN.

Lins, M. P. E. \& Meza, L. A. (2000), Análise envoltória de dados: perspectivas de integração no ambiente do apoio à decisão. Rio de Janeiro, COPPE/UFRJ. 
Senra, L. F. A. D. C., Nanci, L. C., Mello, J. C. C. B. S. \& Meza, L. A. (2007), 'Estudo sobre métodos de seleção de variáveis em DEA', Revista Pesquisa Naval (27), 191-207.

Silva, F. G. F., Martins, F. G. D., Rocha, C. H. \& Araujo, C. E. F. (2011), 'Análise exploratória da eficiência produtiva dos portos brasileiros', Revista Transportes . 